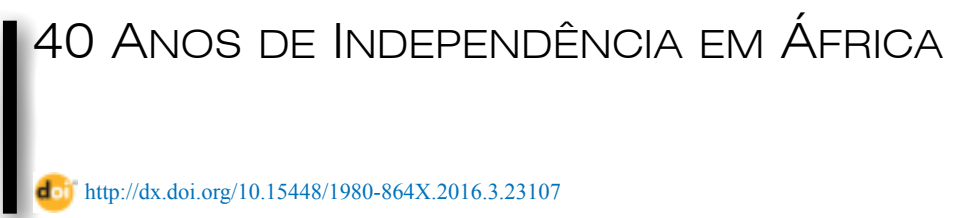

\title{
São Tomé e Príncipe: reflexões sobre alguns aspectos de sua história agrícola no pós-independência
}

\author{
São Tomé and Principe: Thoughts on aspects of \\ its post-independence agricultural history \\ Santo Tomé y Príncipe: reflexiones sobre aspectos \\ de su historia agrícola en el pos-independencia
}

Marina Berthet*

\begin{abstract}
Resumo: O artigo proposto para o dossiê apresenta reflexões sobre aspectos da história agrícola do país no momento da independência e no pós-independência. A perspectiva escolhida apresentou-se como pertinente para refletir sobre a política do país durante as décadas que seguiram a Independência. As relações estabelecidas entre os membros do governo independente e os trabalhadores agrícolas, as ambivalências do discurso político governamental no momento da nacionalização das terras e sua distribuição são abordados aqui para um balanço sobre a Independência com data oficial de comemoração em 12 de julho de 1975. Procuro demonstrar que as diversas propostas políticas aplicadas ao setor agrícola levaram a uma acentuação da invisibilidade de minorias - principalmente a mão de obra imigrante - que são eventualmente reconhecidas como atores chaves da história agrícola de São Tomé e Príncipe. A gestão da distribuição da terra após a nacionalização do território provocou tensões sociais que acirraram reivindicações identitárias e evidenciaram a consolidação de determinados atores sociais na esfera do poder político. Notas de trabalhos de campo efetuados em 1999-2000 e 2003-2004 e algumas fontes primárias e secundárias enriquecem o texto de informações e auxiliam na argumentação das principais ideias.
\end{abstract}

Palavras-chave: São Tomé e Príncipe; Nacionalização das terras; Reforma Agrária; Independência

Abstract: The article proposed for the dossier presents reflections on aspects of the country's agricultural history at the time of independence and post-independence. The chosen approach presented itself as relevant to reflect on the country's politics during

\footnotetext{
*Professora de História da África - PPGH/GH da Universidade Federal Fluminense.<marinaannie@, gmail.com> < dados biográficos/biographic data $>$
} 
the decades that followed independence. Aspects of the country's agricultural history make up the thread chosen to guide this article. The relations between the members of the independent government and agricultural workers, the ambivalences of the state's political discourse at the time of the nationalization of land and its distribution are here analyzed to begin a balance of the political independence (official date of July 12, 1975). I try to show that the various policy proposals applied to the agricultural sector led to an accentuation of the invisibility of minorities - especially the immigrant labor - that are eventually recognized as key actors in the agricultural history of São Tome and Principe. The management of land distribution after the nationalization of the territory caused social tensions incited identity claims and highlighted the consolidation of certain social actors in the sphere of political power. Notes from field work carried out in 1999-2000 and 2003-2004 and some primary and secondary sources enrich the text information and assist in arguments for the main ideas.

Keywords: São Tomé and Príncipe; land nationalization; land reform; Independence

Resumen: El artículo es una propuesta al dossier y presenta reflexiones sobre los aspectos de la historia agrícola de Santo Tomé y Príncipe en el momento de la independencia y después de la independencia. El enfoque elegido se presenta como relevante para reflexionar sobre la política del país durante las décadas que siguieron a la independencia. Las relaciones establecidas entre los miembros del gobierno independiente y los trabajadores agrícolas, las ambivalencias del discurso político estatal en el momento de la nacionalización de las tierras son relevantes para hacer un balance de la independencia política con la fecha oficial de 12 de julio 1975. Trato de demostrar que las diversas propuestas de políticas aplicadas al sector agrícola llevaron a una acentuación de la invisibilidad de las minorías - especialmente la mano de obra inmigrante. La gestión de la distribución de la tierra después de la nacionalización del territorio causó tensiones sociales que incitaron a las reivindicaciones de identidad y destacaron la consolidación de ciertos actores sociales en la esfera del poder político. Anotaciones de trabajos de campo realizados en 1999-2000 y 2003-2004 y algunas fuentes primarias y secundarias enriquecen el texto de informaciones y auxilian en la argumentación de las principales ideas.

Palabras clave: Santo Tomé y Príncipe; nacionalización de la tierra; reforma agraria; Independencia

Refletir sobre os quarenta anos de independência de São Tomé e Príncipe tem se revelado um desafio. Desde as comemorações dos cinquenta anos de independência dos países africanos (1960-2010), proceder a um balanço ${ }^{1}$ desse momento político continental tem sido recorrente no âmbito das ciências sociais. Uma das ideias mais debatidas nessa área foi pensar se a independência, símbolo da libertação do julgo colonial e da conquista da liberdade e autonomia plena levou efetivamente a uma ruptura significativa com as instituições

\footnotetext{
${ }^{1}$ Penso, por exemplo nos inúmeros livros, artigos que foram publicados no ano de 2010 por autores africanos e outros ou ainda nas múltiplas conferências, nos seminários organizados para falar sobre $\mathrm{o}$ assunto.
} 
estabelecidas no tempo colonial. Diversas indagações foram feitas, entre elas: as propostas políticas dos jovens governos africanos atenderam às demandas das populações das novas nações? Aos poucos, artistas, jornalistas, políticos, trabalhadores, pesquisadores (etc.) participaram desses diversos debates ${ }^{2}$. Essa participação popular ocorreu de formas diversas nas ex-colônias portuguesas. No caso de São Tomé e Príncipe, precisamos voltar ao momento da conquista pela independência para entender o processo que levou à proclamação da Nação libertada da presença colonial e analisar quais são os atores que participaram desse momento-chave. A independência do país teve a particularidade de se concretizar fora das ilhas a partir de negociações com as autoridades portuguesas e é tida como a única negociação pela independência entre as ex-colônias portuguesas - que não levou a nenhum conflito armado contra Portugal. Após os contatos diplomáticos ocorridos entre os quadros políticos de STP e diversos membros do governo português, houve a assinatura de um acordo - em 26 de novembro de 1974 entre Portugal e o Movimento de Libertação de São Tomé e Príncipe (MLSTP), único movimento político que representava a Nação nos anos setenta. Com isso, a participação das camadas populares foi reduzida a uma mera atuação nas comemorações da Independência em 12 de julho de 1975. O primeiro presidente da República, Manuel Pinto da Costa, apostou na implementação de um regime socialista com um partido único. Consequentemente, um dos balanços que foi feito sobre esse período pode ser resumido à principal ideia de que as medidas e políticas adotadas levaram a algumas mudanças sem necessariamente provocar uma transformação drástica do sistema econômico, contrariando as promessas iniciais do governo e as esperanças dos trabalhadores agrícolas.

\section{Os principais atores da história agrícola de São Tomé e Príncipe no momento da Independência}

A partir do resumo de um conto da tradição oral da ilha de São Tomé, apresentado a seguir, pretendo esboçar um retrato dos atores-chaves

\footnotetext{
2 Diversos autores como Mbembe, A. Diouf, M. classificados como fazendo parte da corrente pós-colonial apresentaram suas reflexões e evidenciaram o balanço ambíguo das independências políticas africanas. O ator e cineasta Wolimité Sié Palenfo indagou: "A colonização parou no primeiro dia da Independência dos países africanos?"A indagação foi feita bem antes da comemoração dos cinquenta anos de independência quando Wolimité Sié Palenfo realizava (em codireção) o documentário Mémoire entre deux rives, 2002.
} 
da cena agrícola do país. Em seguida, resumo a situação social de alguns desses atores no contexto agrícola pós-independência do país e procuro entender como foram afetados por diversas tomadas de decisões governamentais. O conto intitulado: "Um grão de milho é um preço dum escravo" ${ }^{3}$ nos apresenta o trabalhador agrícola - o serviçal - e mais três personagens principais: Sum Alê, dono de terras que procura mão de obra, a Tartaruga, conselheira de Sum Alê e o administrador colonial que administra as terras sob domínio colonial. A maioria das terras produzia cacau destinado à exportação ${ }^{4}$.

Sum Alê se irritava ao ver o cacau apodrecer na sua roça e reclamava da falta mão de obra necessária para a colheita da safra. A Tartaruga ofereceu sua ajuda e pediu a Sum Alê uma garrafa cheia de milho e afirmou "um grão de milho é um preço dum escravo. Dê-me um grão de milho". Sum Alê reclamou, ameaçou expulsar a Tartaruga intrometida, mas decidiu satisfazer seu pedido pouco exigente. A Tartaruga iniciou sua viagem à procura de mão de obra barata que pudesse ser contratada para trabalhar na roça de Sum Alê. Após viver várias peripécias e empregar alguns subterfúgios, a Tartaruga consegue obter uma galinha e um boi, mas ainda procurava encontrar um escravo para trabalhar nas terras de Sum Alê. Em seguida, parou na roça ${ }^{5}$ de um administrador que passava a cavalo. Após ser interpelada para apresentar as razões de sua presença numa propriedade colonial, a Tartaruga se defendeu explicando que estava procurando o serviçal - que, no momento do diálogo entre os dois personagens principais, estava nas proximidades trabalhando - que tinha aleijado o boi de raça de Sum Alêt. O serviçal sofreu imediatamente brutal chicotada por parte do administrador branco que retrucou: "Entrega este animal ao Rei porque a Curadoria prometeu-me mais cem bestas para o trabalho". Mais do que satisfeita, a Tartaruga

\footnotetext{
3 Conto recolhido por Françoise et Jean-Michel Massa, traduzido para o francês por Emilio Giusti e traduzido por mim para a versão portuguesa. Não foi possível ter acesso à versão original que é na língua forro. Com isso, é necessário esclarecer que o conto perdeu muito em informações. Apesar dessas limitações, creio que esse conto os dá uma ideia do imaginário local construído em torno do trabalho agrícola.

${ }^{4}$ É imprescindível lembrar que os contos da Tradição oral africana não possuem nomes de autores e também não são datados. No entanto, alguns elementos como menção de um administrador colonial, de um serviçal, a produção de cacau nos indicam que o conto se refere a um período colonial que precede a independência.

5 Complexo agrícola colonial visando a produção de monocultura de exportação como a do cacau. Até os dias de hoje, a roça designa, ao mesmo tempo, as terras e estruturas agrícolas herdadas do tempo colonial, as parcelas de terras recebidas no momento da reforma agrária, as pequenas glebas com culturas alimentares.

6 No conto, a Tartaruga chama Sum Alê pelo seu nome ou também o chama de Rei.
} 
levou o trabalhador. Ao entrar no palácio de Sum Alê, apresentou o serviçal e perguntou: "Sum Alê, afinal um grão de milho é ou não o preço de um escravo"?

Creio relevante interpretar um conto local da Tradição Oral de São Tomé e Príncipe com intuito de desvendar aspectos da história agrícola que marcaram o imaginário popular ${ }^{7}$. No entanto elementos como - os principais atores da vida agrícola, o valor do trabalho agrícola (que vale um grão de milho), os mecanismos característicos do sistema colonial e suas instituições como a Curadoria dos indígenas, um olhar "local" sobre o momento colonial - se mantiveram como continuidades no texto final.

Sum Alê, nome em forro ${ }^{8}$ traduzido por senhor, é natural da ilha, representa os nativos, os descendentes de escravos negros libertados, também conhecidos como forros ${ }^{9}$. No conto, Sum Alê é conhecido por todos, inclusive pelo administrador colonial, como Rei. Ele comprova a existência de um poder político e econômico local, elemento a ser destacado em tempos coloniais. É dono de terras que produzem cacau, possui palácio e escravos, é reconhecido e respeitado pelos brancos. Sum Alê se queixa da falta de mão de obra para trabalhar a terra. Vale lembrar que no momento da segunda colonização portuguesa, com a introdução do cacau (oriundo do Brasil) na ilha do Príncipe no início do século XIX, a maioria das terras das duas ilhas vão ser exploradas e trabalhadas para se tornarem parte de um complexo agrícola colonial maior do qual os donos locais vão ser progressivamente excluídos. No conto, não há menção desse episódio histórico. A queixa da falta de mão de obra (por parte dos donos de terra locais e estrangeiros) para trabalhar a terra sempre foi o argumento chave utilizado em diversas épocas da

\footnotetext{
Enfatizo que o conto foi traduzido. Posteriormente, resumi o texto, interpretando o e fazendo escolhas dos elementos que considerei pertinente. Isso me distancia da fonte oral. Considero que se trata de um novo documento inspirado de um conto oral, mas que perdeu parte de seus significados nas etapas de trabalho mencionadas anteriormente.

8 O forro é uma das línguas faladas em São Tomé e Príncipe classificada, em termos linguísticos, como crioulo porque $70 \%$ do seu léxico vem do português.

9 No momento da independência são considerados nativos da ilha de São Tomé e Príncipe: os forros, os filhos da terra, os angolares e os nativos de Príncipe (chamados também de moncós). Gonçalves (1973, p. 52) explica a seguir diferença entre os forros e os filhos da terra: "O forro é o antigo escravo liberto que ficou a viver na ilha, recebeu esta designação nada tendo ver com a população crioula nascida séculos atrás dos contactos entre portugueses e africanos, pois estes eram livres desde o nascimento". Essas categorias foram criadas ao longo da segunda colonização portuguesa (1830 aproximativamente). Neste artigo, não pretendo questionar ou definir essas categorias por considerar que isso deveria ser fruto de um outro artigo. As categorias são utilizadas como tal porque são constantemente utilizadas pelos santomenses, cientistas sociais, etc.
} 
vida colonial e pós colonial para justificar os problemas enfrentados em termos agrícolas como falta de rendimentos, fraca produção de cacau, etc. Vale lembrar que os donos de terra locais encontravam muitos obstáculos para contratar a mão de obra imigrante, reservada aos roceiros portugueses que ocupavam as terras mais férteis das duas ilhas.

A Tartaruga ${ }^{10}$ é o segundo personagem em ordem de aparição no conto. É um dos animais mais citados nas Tradições Orais africanas (principalmente em contos dos Camarões ou de outras regiões e países da África central). A referência à tartaruga é um estratagema para evidenciar alguns comportamentos humanos, tendo apenas ela o nome de um bicho ${ }^{11}$. É um personagem interesseiro que procura manter seu papel de conselheira a serviço de Sum Alê, mas sem ameaçar sua autoridade ou criticar a ordem estabelecida - a Tartaruga não se comove, por exemplo, com o castigo dado ao serviçal pelo administrador colonial. O jogo político instituído pela Tartaruga conforta Sum Alê na sua autoridade mas ao mesmo tempo mostra que seu poder depende também do bicho. A Tartaruga mantém, implicitamente, a lógica interna e colonial ao acusar injustamente um serviçal de ser ladrão e depois o leva como mão de obra para o "Rei". Os maus tratos sofridos pelo serviçal não espantam a Tartaruga. Como interpretar esse silêncio? Seria uma forma de silenciar as relações tensas e violentas entre nativos e os portugueses? A maneira como a Tartaruga trata o serviçal também provoca questionamentos, mas confirma que este bicho não valoriza o trabalhador nem atribui um valor simbólico significativo ao trabalho agrícola.

Uma pergunta paira no ar: se a Tartaruga é a metáfora de um homem, qual ator da vida política são-tomense ela representa? É difícil responder. Por sua vez, o administrador colonial é um ator relevante do dinamismo político no tempo colonial e do conto. Administra terras, concede um serviçal ao Rei para sustentar a ordem política existente, garantir boas relações diplomáticas com o poderio local, ele tem liberdade para maltratar seus trabalhadores. No conto, a chicotada dada pelo administrador simboliza os atos violentos perpetrados no período colonial. Interpreto que existe uma denúncia desses comportamentos

\footnotetext{
${ }^{10}$ Para mais informações, consultar o artigo de Denise Paulme "typologie des conte africains de Décepteur". <http://www.persee.fr/doc/cea_0008-0055 1975 num_15 60 3361>.

${ }^{11}$ Cabe ainda notar que o animal no conto é o nome utilizado pelo administrador para falar do serviçal!
} 
coloniais, ainda que de forma velada e indireta. A menção à Curadoria dos indígenas nos permite entender o seu lugar no imaginário local: fornecedora de mão de obra barata para os roceiros portugueses. Ao entregar o trabalhador, o administrador afirma que: "a Curadoria poderá facilmente the fornecer mais 'cem novos deles'...". A Curadoria era percebida como intermediária entre os patrões de roças e os escravos que trabalhavam na cultura de cacau. Ainda que responsáveis pela vigilância do cumprimento das leis sobre o trabalho e os contratos de trabalho, os agentes da Curadoria se tornavam suspeitos aos olhos da população local, já que muitas vezes, defendiam os interesses dos roceiros coloniais e usavam estratégias que consolidavam alianças estabelecidas com esses.

No texto, o serviçal não é um protagonista principal. É tratado de forma parecida pelo administrador colonial e pela Tartaruga. Diante de um cenário com relações complexas e que foram se tornando mais tensas (à medida que as terras se tornavam propriedades coloniais) entre portugueses e os nativos, os colonizadores privilegiaram a mão de obra agrícola que provinha de outras colônias do Império português para trabalhar nas suas roças. É essa mão de obra importada e seus descendentes que vão se tornar os moradores das roças e atores principais da vida agrícola, produzindo as principais culturas de exportação do país. O serviçal é o personagem silencioso do conto, não protesta contra as acusações injustas, nem quando é vítima da violência do administrador, nem quando é levado para servir Sum Alê. O silêncio e a passividade que caracterizam o personagem nos fornecem informações sobre o olhar local em relação a essa mão de obra estrangeira. Elementos como o silêncio, o status de um serviçal, chamado também de escravo, que sempre trabalha, sofre maus tratos, cujo trabalho (e vida) vale "um grão de milho" foram utilizados de forma constante para definir os trabalhadores agrícolas na perspectiva local. Nesse sentido, o texto se refere a um marco na história de invisibilidade social ${ }^{12}$ vivida pelos imigrantes.

\footnotetext{
${ }^{12} \mathrm{O}$ conceito de social invisibility aparece na literatura em psicologia nos anos quarenta. Um dos autores mais citados nessa discussão é o Sartre quando define que essa expressão implica que, para superar essa invisibilidade, o indivíduo precisa do reconhecimento dos outros indivíduos. Sarte (1947). Posteriormente Barel nos anos sessenta recupera essa ideia no seu livro sobre marginalidade social. Em contexto de migração, como é o caso, a invisibilidade social adquire novos contornos. A contribuição do sociólogo Alex Honneth (2005) nos leva a adotar aqui sua perspectiva. É através do não-reconhecimento de determinados atores sociais pelo resto da sociedade que se reforça a ideia de invisibilidade social.
} 
Por fim, as roças são o principal espaço agrícola mencionado no resumo. A análise desse espaço agrícola é ligada aos processos que participaram da construção do universo social de São Tomé e Príncipe. Na história agrícola do país, as roças do cacau colonial representaram, no último quartel do século XIX, a matriz principal do setor agrícola e ocupam as maiores superfícies das duas ilhas. A roça, como estrutura agrícola produtora de cacau, é ao mesmo tempo uma unidade econômica e sociocultural que vai induzir uma organização espacial específica, estabelecer uma hierarquia social que vai marcar o período pós independência. Gonçalves (1972, p. 53) considera que em São Tomé: "A roça (...) exerce uma força centrípeta sobre o resto do território (...) constitui (...) toda uma configuração de matriz própria e implicações bem fundas no modo de ser, pensar e agir duma grande parte da população". As roças se tornaram ainda no período colonial um lugar estratégico no qual era possível defender ideias relativos à civilização pelo trabalho, à constituição de um modelo de "colônia de plantação"13. A denúncia desse sistema implementado durante o regime colonial, a questão do trabalho e da contratação de uma mão de obra imigrante explorada, as relações de poder marcadas pela exploração vão servir de fonte de inspiração para intelectuais, homens políticos e escritores são-tomenses. A roça vai se tornar um dos elementos mais recorrentes da luta anticolonial, nos discursos políticos nacionalistas, na produção literária e musical das duas ilhas.

Diante desse contexto político contestatório, o desmantelamento das roças coloniais (juridicamente eram sociedades e companhias agrícolas) após a Independência parecia inelutável por serem diretamente associadas ao período colonial e a uma política portuguesa que visava apenas a exploração das terras com culturas rentáveis e de exportação. Os membros do Comitê de Libertação de São Tomé e Príncipe (doravante CLSTP) que se tornou posteriormente Movimento de Libertação de São Tomé e Príncipe (doravante MLSTP) criticavam o fato de que mais de dois terços de solo cultivado pertenciam a um punhado de estrangeiros. No entanto, não foi o desmantelamento que foi planejado para dar início a uma nova história agrícola da jovem República e sim apenas uma nacionalização dessas roças. Assim sendo, as roças consideradas o símbolo da "miséria no seio do nosso povo" e "o obstáculo principal ao progresso geral, ao avanço do processo revolucionário" - não eram mais o problema central da política agrícola do país.

\footnotetext{
${ }^{13}$ Expressão sugerida por Mário Pinto de Andrade.
} 


\section{Nacionalização das terras e o envolvimento do cidadão: as tentativas do governo independente em criar novos hábitos em relação ao trabalho agrícola}

A questão das roças foi submetida à apreciação do comício de massas realizado em 30 de setembro de 1975 na Praça Ion Gato". Dirigindo-se ao povo, o presidente da República perguntava:

"Fomos ou não fomos explorados durante centenas de ano pelo colonialismo fascista português? Somos ou não somos ainda explorados pelas companhias agrícolas estrangeiras existentes no nosso país? Temos ou não temos o direito de nacionalizar as terras, de tomar as terras que foram roubadas ao nosso povo? O que é que a Assembléia Geral do povo de S. Tomé e Príncipe decide... [sobre as roças] ... Tomamos ou não tomamos essas roças? (Grito unânime do povo: Tomamos! Tomamos!)" (Discurso proferido pelo então presidente da Republica, Pinto da Costa em 30 de setembro de 1975)

Tomamos! O povo santomense teria assim participado de forma ampla e ativa no processo de nacionalização das roças? Ao denunciar as roças como sistema herdado do período colonial, os membros do MLSTP (sendo que nenhum deles trabalhou como mão de obra nas terras coloniais) foram considerados atores políticos de destaque que expressaram sua solidariedade com os serviçais e porque todos esses sujeitos da história se uniam por ter vivido a experiência africana compartilhada da dominação colonial. No entanto, esse sentimento de partilha de uma mesma experiência de violência parece ter sido atrelado a outros interesses políticos, como afirma Nascimento (2001, p. 210): "A ideologia que foi construída acima da vida nas roças é mais ligada à própria ideologia dos autores do que uma tentativa de se aproximar da realidade rural vivida pelos escravos e mais tarde pelos serviçais. Essa ideologia se construiu em reação ao regime colonial, como parte de um discurso político em que um dos argumentos chaves é a exploração da mão de obra nas roças como sendo da inteira responsabilidade do governo colonial português" ${ }^{14}$. Nota-se uma oposição entre o resumo do conto em que um dono de terra local recorre a uma mão de obra

\footnotetext{
${ }^{14}$ Em São Tomé, a palavra "serviçais" surgiu logo depois a abolição da escravidão para designar a mão-de-obra agrícola. Outro nome comum é "contratados" para designar as mesmas pessoas.
} 
escrava e o discurso político pós-independência que atribui ao governo colonial a inteira responsabilidade das práticas escravagistas. Vale frisar que, de modo geral, os atores políticos atuando no governo, os membros do MLSTP, militantes e grupos economicamente mais favorecidos viviam na cidade de São Tomé, focavam parte de sua atenção e de seus discursos no destino das roças coloniais, mas não tinham contato com o mundo das roças, nem conhecimentos agrícolas prévios. Essas distância e ausência de contatos eram atribuídas ao sistema colonial opressor que tinha se baseado numa clara divisão espacial, social e cultural entre os diferentes grupos locais e a mão de obra imigrante. As divergências entre angolares, forros, filhos da terra e a mão de obra imigrante (vinda de Angola, Moçambique e Cabo Verde) eram também consideradas consequências diretas da política colonial opressora ${ }^{15}$. É incontestável que o MLSTP carecia de uma base popular oriunda do meio rural e receptiva às suas ideias políticas. Entre outras razões, considero que o fato desse movimento político ter sido criado no exterior e ter se consolidado graças a são-tomenses no exílio provocou um estranhamento maior entre uma representação política dos forros e dos filhos da terra e os outros componentes sociais como angolanos, moçambicanos e cabo-verdianos que não possuíam representações políticas.

Dois meses depois da Independência, no calor das comemorações da recém-liberdade conquistada, Manuel Pinto da Costa, líder do partido MLSTP e então presidente da República, pronunciou um discurso em 30/09/1975, anunciando a nacionalização das roças. Esse momento histórico passou a ser considerado posteriormente, como Maino propõe, como o ato fundador da nação são-tomense. No seu discurso pronunciado na praça da Independência, Manuel Pinto da Costa afirmou que a nacionalização significava a desapropriação das terras dos seus atuais donos (proprietários coloniais) e a libertação definitiva do julgo colonial. Apontara também para a necessidade de implementar uma reforma agrária e manter a produção do cacau ${ }^{16}$ destinado à exportação. A nacionalização começou efetivamente no fim do mesmo ano. Para cumprir os objetivos estabelecidos, era preciso modificar a organização e a gestão das roças. Em 1978, o Estado são-tomense transformou as roças

\footnotetext{
${ }^{15}$ A descrição da complexidade social de São Tomé e Príncipe não cabe nesse artigo, porque implicaria uma apresentação histórica de cada grupo social. Optei por mencionar os atores chaves do contexto pós-independência da forma como são nomeados localmente.

${ }^{16} \mathrm{Em}$ 1991, 90\% das exportações deste produto totalizaram a soma de 5,5 milhões de dólares, enquanto no mesmo período, o país financiou 24 milhões de dólares de importações.
} 
em 22 empresas agrícolas, sendo este número reduzido posteriormente a 15 empresas ${ }^{17}$. A reorganização das roças em empresas agrícolas levou a consolidação de cargos que já existiam no final do tempo colonial, mas que passaram a ser definidos com outros nomes. Por exemplo, o administrador de roça passou a ser chamado de diretor de empresa. A maioria desses cargos de mais responsabilidade passou a ser ocupada por membros do MLSTP, enquanto capatazes e outros empregados ocupando funções mais administrativas ou técnicas foram mantidos nos seus postos. Ou seja, não houve uma renovação significativa dos empregados que já ocupavam esses cargos na véspera da independência. Na nova organização das empresas agrícolas, a maioria das pessoas previstas para ocupar os cargos de responsabilidade não era formada nessa área. Por sua vez, os trabalhadores agrícolas de roças permaneciam como mão de obra. É por essa razão que Eyzaguire (1989, p. 676) avalia que depois da independência as Empresas Agrícolas mantiveram as principais características da organização de trabalho planejada nas roças coloniais. O autor analisa que essa situação levou a imobilizar uma parte significativa da população em "status inferior". Em suma, a nacionalização não transformou - como anunciado pelo governo - fundamentalmente esse "objeto colonial" que permaneceu na sua estrutura, arquitetura e simbologia análogo às roças dos derradeiros anos coloniais.

As roças estavam no cerne do debate sobre o futuro agrícola do país e sua mão de obra agrícola imigrante era a população que morava nas roças. Os imigrantes passaram a estar no centro das atenções do MLSTP. Os membros políticos afirmavam que o bem estar da população e a melhoria de suas condições de vida constituíam objetivos prioritários da jovem Nação. Nesse período, as roças se tornaram novamente um espaço estratégico para as autoridades políticas e para a defesa de suas ideias políticas do MLSTP. "Tratou-se, no entanto, de um dos melhores meios para a afirmação e instalação do Partido Único que implantou nelas os seus comitês com os seus responsáveis a ocupar lugares de destaque na gestão econômica das empresas sem qualquer perfil" (CEITA, 2004, p. 4). Nesse mesmo período (os anos oitenta), o Partido procurava manter sua política de boa vizinhança para se aproximar dos trabalhadores agrícolas, recrutar potenciais membros para o Partido,

\footnotetext{
${ }^{17}$ Segundo Maino (2004), havia em 1979 cerca de 14.600 trabalhadores agrícolas morando nas roças de São Tomé e Príncipe, 10.840 em 1983 e 7.742 em 1991. Existem diversas controvérsias em relação aos dados (hectares e número de trabalhadores). A minha intenção é aqui dar uma ideia aproximativa desse mundo rural em números.
} 
garantir determinados privilégios para alguns dos seus membros que se tornaram os novos diretores das Empresas. Na tentativa de obter maior adesão das "massas trabalhadoras", o novo governo aumentou os salários dos trabalhadores no primeiro ano da independência. Moradoras ${ }^{18} \mathrm{da}$ roça Agostinho Neto lembram que os salários foram reajustados na ocasião, permitindo que as mulheres ganhassem o mesmo salário que os homens.

O governo organizou ainda visitas regulares de técnicos formados para administrar as roças. Essa experiência se concretizou com a criação de "Comissões Administrativas Provisórias" 19 . Entre diversas tentativas de mobilização dos moradores das roças, os membros do MLSTP faziam a apologia do trabalho, enaltecendo o papel do cidadão apresentado como imprescindível para o desenvolvimento agrícola e econômico do país. Paradoxalmente, esse trabalho devia servir a manter a produção e exportação do maior símbolo da dominação colonial: o cacau. Os interesses do governo em relação às roças e aos seus trabalhadores levavam os membros políticos a tentar construir novos laços políticos para garantir a permanência dessa preciosa mão de obra nas roças, onde o MLSTP precisava testar sua ideologia socialista. Assim, foram criados comitês de ação nesse complexo rural com objetivo de propor espaços de convivência, propiciar debates políticos e ouvir queixas dos trabalhadores. Segundo o relatório oficial, os comitês de ação: “(...) não foram apenas grupos de partido, mas também os embriões dos novos organismos do poder que se preparavam para substituir os antigos administradores (...)" (Proclamação da RDSTP, p. 383 12/07/75-12/07/78). Cada Comitê de Ação do Partido era administrado por um delegado do Comitê, encarregado de coordenar reuniões com os trabalhadores. Esses comitês eram considerados pelo Partido "as verdadeiras organizações de base", mas, no imaginário dos trabalhadores, esses comitês nem sempre eram visto com bons olhos, já que as pessoas alegavam não saber as reais funções das organizações dentro das roças e por vezes consideravam os delegados como inimigos ou "bufos" 20 .

\footnotetext{
${ }^{18}$ Conversa informal realizada em Agostinho Neto em janeiro de 2005.

${ }^{19}$ Cabe ressaltar que a nacionalização é por vezes chamada de reforma agrária. A partir das orientações definidas pelo Ministério da Agricultura e Reforma Agrária, as comissões tinham como objetivo principal a aplicação da reforma agrária.

${ }^{20}$ Termo empregado pelos moradores de roças e também por Manuel Pinto da Costa quando tentava reabilitar os comitês aos olhos dos trabalhadores. No seu discurso durante a inauguração da sede dos comitês MLSTP/JMLSTP da empresa agrícola Boa entrada, em março de 1977, Pinto da Costa fez questão de desconstruir essa imagem negativa, apontando para o fato que, em hipótese nenhuma, o comitê seria um espécie de informante de atividades ilegais, por exemplo, ou contrárias à ideologia do partido.
} 
O MLSTP apresentava os comitês como órgãos representativos dos trabalhadores em complemento aos Grupos de Vigilância e Defesa Popular e das Milícias Populares ${ }^{21}$. A discussão em torno do papel dos Comitês, se eram capazes de representar efetivamente os trabalhadores, nos dá uma ideia das dificuldades encontradas pelo Partido para obter uma adesão política dentro das roças. Além de manter as estruturas agrícolas em funcionamento, o governo independente optou (como foi dito anteriormente) por manter o foco na produção de cacau (História Oficial de STP, 1985, p. 405). A justificativa dada pelo MLSTP se embasa numa avaliação geral das condições econômicas e do desenvolvimento do sector agrícola. Os governantes argumentavam o fato de que a diversificação agrícola - isto é, um investimento maior em culturas alimentares com intuito de garantir uma autonomia alimentar das famílias dos trabalhadores agrícolas - só poderia ser realizada a partir de investimentos de capital que, paradoxalmente, só seriam obtidos com o aumento da produção do cacau e sua exportação. Para o poder político estabelecido, a obtenção de divisas graças à venda do cacau permitiria também a aquisição de bens importados.

No espaço agrícola constituído pelas roças, manter a produção e venda do cacau significava para o governo ter que garantir a participação da mão de obra agrícola que logo depois da independência começa a enxergar a migração como solução para as dificuldades enfrentadas nas roças. Para fixar a mão de obra e garantir a produção de cacau, o governo procurou estimular a participação de todos seus cidadãos nos trabalhos agrícolas das roças e aumentar a "produtividade do trabalho"22. Progressivamente, a questão da participação da população na construção da Nação vai se tornar a espinha dorsal das políticas governamentais sucessivas. Logo após iniciar a nacionalização das roças, o governo procurou mobilizar não só os trabalhadores, moradores das roças recém-nacionalizadas, mas também a população são-tomense, moradora de centros urbanos, ou núcleos próximos à cidade, condicionando o sucesso da reforma agrária à sua participação ${ }^{23}$. Caminhões eram disponibilizados para ir buscar funcionários públicos que trabalhavam nos escritórios, repartições, oficinas da cidade capital São Tomé e os levavam para as roças para participar de diversas tarefas agrícolas. Para

${ }^{21}$ Os quais, cabe ressaltar, possuíam um caráter paramilitar.

${ }^{22}$ Ideia formulada no discurso em comemoração ao $2^{\circ}$. aniversário da nacionalização das empresas agrícolas.

${ }^{23} \mathrm{O}$ governo institui, por exemplo, o dia três de fevereiro 1976 como "dia do trabalho e da militância." 
alguns deles, ir para roça era o primeiro contato com esse mundo agrícola claramente associado (no imaginário local) à repressão e violência colonial. As roças eram afastadas - em termos geográficos e sociais - dos centros urbanos, luchans ${ }^{24}$ e outros núcleos populacionais e constituíam espaços isolados ${ }^{25}$. As campanhas de trabalho cívico e voluntário começaram, segundo Sr. Onofre, por volta de novembro de 1975 e permaneceram durante quatro a cinco anos depois da independência ${ }^{26}$. Essas campanhas foram realizadas, sobretudo nos períodos do auge de produção de cacau (de outubro a dezembro de cada ano). Os servidores publicos da cidade bem como os estudantes eram levados às plantações para jornadas de trabalho, para apanhar ou quebrar o cacau.

Segundo o jornalista Ambrósio Quaresma ${ }^{27}$, o governo independente decretou a necessidade do trabalho cívico nas roças para trabalhar a terra e com objetivo de garantir a produção de cacau. $\mathrm{O}$ entrevistado afirma que "Cada fim de semana era euforia. Os trabalhadores da função pública iam ajudar as empresas nas roças. Éramos todos da mesma família". Euforia, provavelmente ligada às comemorações da Independência, mas que contrasta com o comentário de Nazaré Ceita que aponta para a desconfiança por parte dos funcionários que eram obrigados a conceder um dia para cumprir tarefas agrícolas. Para Nazaré Ceita (2004, p. 4): “A roça era, até este momento, um espaço enigmático hermético e coercitivo pelo que a maior parte dos novos trabalhadores que passaram a prestar serviço no sector agrícola iam munidos de um espírito de desconfiança e de um desconhecimento total das regras de produtividade". No decorrer da entrevista, perguntei a Quaresma como eram organizados os trabalhos voluntários e cívicos dentro dos serviços públicos. O jornalista respondeu:

Foi depois da independência de 1975 a 1983 com os funcionários ${ }^{28}$ do Estado. Havia slogan de aumento da produção e da produtividade para desenvolver o país. Os trabalhadores da administração pública numa segunda, terça, quarta-feira iam nas roças trabalhar. Tinha muito café em Monte Café. Todos os trabalhadores da comunicação social iam partir cacau. Havia um comitê político em cada serviço, e tinha uma ligação com partido no poder. Participar dos trabalhos

\footnotetext{
${ }^{24}$ Aglomerações - termo forro localizadas entre os centros urbanos e as roças.

${ }^{25}$ Apesar desse isolamento geográfico, é preciso mencionar a existência de roças e de relações sociais entre, por exemplo, serviçais das roças e angolares ou serviçais e forros.

${ }^{26}$ Segundo Armindo Vaz, os trabalhos cívicos visando a colheita de cacau foram impostos entre 1977 e 1980.

${ }^{27} \mathrm{Na}$ época em que foi entrevistado (2000), Quaresma era redator do jornal $O$ Parvo.

${ }^{28}$ Funcionários de todos os setores (administrativo, educacional, saúde, etc.).
} 
era obrigatório, quem não fosse apanhava falta. A $3^{\mathrm{a}}$ falta, já seria vigiado. Membros do governo, até o Presidente da República, participaram desses trabalhos. Teve bons efeitos. Mas as pessoas não sabiam tirar bem o cacau das árvores e assim penetrava a doença em árvores boas de cacau.

A observação do Quaresma nos leva a entender que os funcionários eram obrigados a participar das tarefas agrícolas, possuindo ou não noções básicas em agricultura. Se completamos essa observação com o comentário de Nazaré Ceita, podemos perceber que a questão da capacitação se tornou problemática para o governo nacional. Sem falar de questões ligadas a status social em que dificilmente funcionários ligados aos ministérios aceitavam de bom grado realizar esses trabalhos ${ }^{29}$. O Estado iniciou uma experiência piloto em três empresas agropecuárias visando estabelecer "normas de trabalho". Isso consistia em estabelecer parâmetros de produtividade em função das tarefas realizadas: "Para a apanha", por exemplo, o número de sacos enchidos durante um dia por um trabalhador que pode variar entre seis e vinte é estabelecido pelas características do terreno (se é muito acidentado, pouco ou normal)"30.

Essa experiência parece não ter sido levada à frente por causa da reação dos funcionários públicos ao caráter obrigatório das medidas ${ }^{31}$. No entanto, o Estado são-tomense tentou, ainda durante alguns anos, ampliar o conteúdo e a forma de participação dos cidadãos em diversos espaços da vida econômica do país e nas roças mais especificamente.

${ }^{29}$ Em conversas informais realizadas no primeiro semestre de 2000, várias pessoas que viveram esse período afirmavam que pagavam a outras pessoas, colegas, para cumprir essas tarefas no seu lugar.

${ }^{30}$ Entrevista realizada com Quaresma, op. cit.

${ }^{31}$ Cabe mencionar que nas últimas décadas do governo colonial, as obras públicas que visavam as melhorias dos serviços públicos em centros urbanos (saneamento básico, construção e manutenção de estradas etc) necessitavam de uma mão de obra constantemente pressionada para garantir a eficiência do trabalho e conclusão rápida das obras. Com isso, diversas vozes (trabalhadores forros e imigrantes) começaram a manifestar seu descontentamento o que levou posteriormente a um violento enfrentamento entre as forças militares coloniais e os trabalhadores das obras públicas e a uma repressão sangrenta que passou a ser conhecida como o massacre de Batepá. O massacre de muitos trabalhadores se inscreveu na memória coletiva como um trauma ligado ao início da resistência política dos são-tomenses. A questão da desconfiança sobre a obrigatoriedade de produtividade do trabalho pode ser entendida como uma das consequências desse episódio trágico. Um episódio que tem uma relevância crucial na construção identitária dos forros. Ele se insere como fato da história colonial e conta com trabalhadores urbanos. Ainda que esses contaram com apoio parcial dos trabalhadores agrícolas, a maioria dos atores principais que reivindicaram seus direitos não moravam nas roças. É importante frisar que durante meus trabalhos de campo nenhum trabalhador cabo-verdiano que estava presente em São Tomé no momento dos eventos mencionou o massacre. 
Portanto, os discursos nacionalistas não correspondiam à realidade social são-tomense e eram notórias as dificuldades dos dirigentes para convencer a população urbana de sua necessária participação nos trabalhos agrícolas. Isto levou o governo a estabelecer leis para diminuir o absenteísmo dentro das roças (como Quaresma menciona) e garantir a disciplinar e a presença regular no trabalho. Os verdadeiros cidadãos eram aqueles considerados pelo MLSTP como os que se destacavam no seu empenho em aumentar a produtividade do trabalho nas Empresas Agrícolas, nas Escolas. É o caso dos operários agrícolas - da antiga roça Rio de Ouro - que teriam comprado, com seus próprios meios, um trator para a empresa. Embora esta informação não tenha sido efetivamente verificada, ela testemunha da estratégia política desenvolvida pelo Estado que fazia questão de valorizar esses "cidadãos comprometidos com o futuro da Nação". Nos discursos políticos, a atuação desses "heróis comuns" do quotidiano era destacada e cada um deles recebia um diploma que simbolizava sua participação cívica. Esses cidadãos eram os novos trabalhadores agrícolas que não moravam nas roças, mas prestavam serviços diários. Aos olhos do Estado, a efetivação da nacionalização só era possível graças ao "apoio de todo o povo" (entenda-se que esse apoio seria espontâneo e voluntário sem caráter de obrigatoriedade).

As medidas de caráter obrigatório levaram a um progressivo absenteísmo por parte dos funcionários que trabalhavam na cidade. A resistência e crítica de diferentes atores sociais aos trabalhos cívicos obrigou o governo a abrir mão dessa proposta. Outra crítica dirigida ao governo era a difusão de um discurso sobre a nacionalização das terras que corresponderia à “(...) destruição da estrutura econômica colonial e a abolição dos privilégios impostos e estabelecidos a favor dos nacionais ou estrangeiros". No entanto, os integrantes do MLSTP parecem ter-se esquecido dos privilégios dos nacionais. Em pleno contexto de nacionalização, membros do governo optaram por não nacionalizar as roças que pertenciam aos forros e iniciar uma campanha de atribuição de terras - conhecida como Envolvimento do Cidadão - a determinados atores da vida agrícola, entre eles alguns já eram donos de terras. Em dezembro de 1981, a Assembleia Nacional Popular definia as linhas diretrizes de um Plano de medidas e ações a serem estabelecidas entre 1982-1985. Este plano previa um programa de atividades visando a recuperação das Empresas Agrícolas e uma tentativa de alterar os resultados negativos da década anterior. Na elaboração desse plano foi decidida a distribuição de terras. As terras com maiores superfícies e 
mais rentáveis seriam administradas com base em contratos de gestão e de arrendamento contando com parceiros estrangeiros. As terras de menores superfícies (por exemplo, entre 10 ha e 400 ha) seriam distribuídas a pessoas que possuíam conhecimentos agrícolas prévios e poderiam demonstrar habilidades em administração de terras. Com isso, o Estado sugeriu que a distribuição fosse realizada mediante aprovação em concurso. No início dos anos oitenta, por ocasião da grande seca de 1983, o Estado são-tomense procedeu à concessão de terras destinadas ao cultivo de culturas alimentares.

Vários beneficiários escreveram cartas ao ministério encarregado da distribuição e receberam um documento oficial de posse. No Plano Perspectivo estatal de 1985-1989, o processo de privatização ou entrega de terras foi mantido. Seibert (2001) afirma que 10.000 hectares de terras foram entregues pelo governo "de acordo com critérios clientelísticos" a determinados beneficiários, sendo que a maioria não era os trabalhadores agrícolas das roças. Essa afirmação é compartilhada por Nazaré Ceita (1995), enquanto Trovoada ${ }^{32}$ considera que terras entre 10 e 400 hectares (com uma distribuição total de 10.400 hectares) foram distribuídos a 439 beneficiários, o que abrangeu $31,5 \%$ das superfícies agrícolas. No seu relatório, a autora (1991, p. 52) questiona a eficiência da política do envolvimento do cidadão e afirma que, do ponto de vista da aplicação, esta política foi um fracasso. Em 1990, 22.243 hectares pertenciam às Empresas Agrícolas, sendo que 1.940 hectares (da superfície das roças) e 1.893 hectares (das terras familiares) produziam cacau ${ }^{33}$. Alguns pesquisadores (por exemplo, Seibert) apontaram para a complexidade das relações entre os membros do Partido e os forros, donos de pequenas propriedades locais que se caracterizaram pelo clientelismo e proteção dos interesses individuais e familiares. O MLSTP, pressionado por instituições internacionais, admitia a necessidade de um envolvimento mais direto da população, mas devia aceitar o fracasso de sua política de obrigatoriedade cívica! Uma entrevista realizada com Sr. Silva ${ }^{34}$ resume as dificuldades do Governo em manter em vigor a participação obrigatória: “(...) entre 1988 a 1992: mudou o sistema de trabalho. Não podia mais aplicar metas de tarefas aos trabalhadores, eles não

\footnotetext{
${ }^{32}$ O relato, de 1991, foi lido durante minha primeira pesquisa de campo e não tem cópia digital ou publicada. Faz parte do acervo do PAPAFPA (antigo PNAPAF). Trata-se de um relato com perspectiva sociológica, e a menção acima está na pagina 52 .

${ }_{33}$ Dados comunicados no ultimo recenseamento agrícola de STP, em 1990.

${ }^{34} \mathrm{Sr}$ Silva atuou como feitor na roça de Plancas I, situada no norte da ilha de São Tomé. Entrevista realizada em 24/02/05 em Guadalupe.
} 
respeitavam. Em vez de capinar raso, capinavam alto, não respeitavam as tarefas, queriam acabar cedo. É a má gestão que provocou isso". O governo são-tomense, membro do Fundo Monetário Internacional (FMI) desde 1977, se engajava, finalmente - com a adoção de um Plano de Ajustamento Estrutural (PAE) - em um processo de negociações junto ao FMI e o Banco Mundial que levaria ao anúncio da (segunda) reforma agrária, em meados dos anos oitenta, que se baseava na renúncia completa à estrutura agrícola "caduca" herdada do tempo colonial português.

\section{Entre planejamento estrutural e reforma agrária, atuação do governo na era desenvolvimentista}

No contexto dos anos noventa, num momento de transição de um regime de Partido único para uma democracia, diversas críticas sociais surgiram colocando em questão a responsabilidade dos nacionais e dos membros do MLSTP em manter seus privilégios no pós-independência. Apesar dos seus discursos políticos que se baseavam na conquista de condições de vida dignas para o povo são-tomense, esses mantinham certos privilégios. Uma das conclusões relativas ao balanço das duas primeiras décadas de Independência era que a manutenção das roças de cacau revelar-se-ia uma escolha política e simbólica por parte dos membros do governo. Segundo Temudo (2008), o modelo de roça implicou, mesmo depois da independência, na contenção da mão-deobra através da "reprodução da indigenização". Sem dúvida nenhuma, não existia um consenso sobre a questão da nacionalização, mas apenas determinados núcleos do Partido Único estavam a favor dessa solução. Romana (1997, p. 172) afirma que: “A questão da política de nacionalização das plantações-roças constituiu, sem dúvida, o fulcro das primeiras situações de luta interna, no quadro pós-independência". Ademais, a herança de 15 anos de Partido Único poderia se resumir na tentativa de se legitimar como autoridade política capaz de sugerir uma história e uma identidade nacionais às quais todos os cidadãos poderiam se identificar. A construção dessa identidade levou o Partido a camuflar diversas tensões e conflitos sociais e valorizar uma suposta homogeneidade da sociedade, herdada de sua união contra a opressão colonial, independentemente das origens dos diferentes grupos sociais ali residentes ${ }^{35}$. Em 1991, em contexto de abertura do

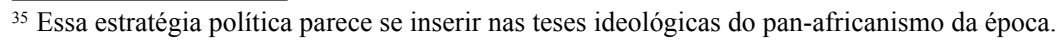


país, a existência de novos partidos políticos, o FMI e Banco Mundial exigiram - dentro dos acordos relacionados ao PAE e contando com a ajuda financeira dessas instituições - que o governo distribuísse uma parte das terras agrícolas (das roças de cacau) aos antigos assalariados agrícolas, enquanto uma outra parte das terras (as mais rentáveis) ficaria sob gestão estrangeira com cogestão de parceiros privados nacionais. No discurso oficial retrospectivo, a implementação do Plano de Ajustamento Estrutural era apresentada como uma solução valorizando a iniciativa individual e os imigrantes, herdeiros legítimos dos que tinham trabalhado durante décadas nas terras de cacau e, até então, não tinham recebido nenhum tipo de compensação ou reconhecimento. O Estado decidia pelo desmantelamento das Empresas agrícolas principalmente por conta das pressões políticas externas. Nos diversos discursos políticos, em que se defendia a distribuição de terras para o benefício dos moradores das Empresas falidas, a decisão era apresentada como fruto de uma autocrítica, do anseio do governo em se modernizar e construir uma nova estrutura agrícola.

(...) a reforma agrária visa à transformação radical das relações de produção até então existentes para dar lugar à criação de um homem novo numa sociedade baseada no progresso e na justiça social. Tornou-se, portanto imperiosa a aplicação de uma política agrária susceptível de modificar as estruturas caducas e de incrementar a produção agrícola mediante o emprego de uma técnica moderna e de equipamento mais eficientes e adequados de forma a permitir a melhoria das condições de vida das massas trabalhadoras (História oficial da RDSTP, 1985).

Não havia menção às organizações internacionais, nem ao fato de que a República de São Tomé e Príncipe já fazia parte do grupo de países considerados em graves dificuldades econômicas. Com essa decisão, o governo parecia finalmente aceitar que os seus assalariados agrícolas tivessem direito em usufruir e posteriormente se tornar donos de pequenas propriedades agrícolas. O governo procurava também limitar o fenômeno de êxodo rural por parte dos antigos trabalhadores agrícolas em direção à antiga metrópole Portugal ou de volta para Cabo Verde $^{36}$.

\footnotetext{
${ }^{36}$ Vários entrevistados Cabo Verdianos afirmaram, durante meus dois trabalhos de campo, que Pinto Da Costa teria disponibilizado aviões para permitir a viagem de regresso sem custos adicionais. Porém, essa iniciativa teria existido apenas nos dois primeiros anos do pós independência.
} 
Nos anos noventa, morar numa roça continuou a ser associado a uma situação depreciativa, porquanto a roça era um lugar onde moravam os descendentes pobres de migrantes cabo-verdianos, sem energia elétrica e, por vezes sem água potável e sem serviços públicos básicos. Em termos de infraestruturas - moradia, água, estradas, e transporte -, as condições passaram a se degradar. Em muitas roças, por exemplo, o sistema de água passou a não fornecer mais a água potável necessária, obrigando muitos dos habitantes a percorrer vários quilômetros a pé para se abastecer na fonte mais próxima. No imaginário nacional, "pertencer à roça" ${ }^{37}$ era (e é ainda) associado a um conjunto de preconceitos, certezas sobre os hábitos e costumes dos moradores considerados isolados dos centros urbanos das duas ilhas ou em espaços de difícil acesso, dado o estado de algumas estradas que levam às antigas roças e a ausência de transporte público. A invisibilidade social que marca os trabalhadores agrícolas imigrantes de São Tomé e Príncipe pode encontrar explicação no fato que o trabalho agrícola é considerado de menos valia, elemento que coincide com o imaginário popular através do conto apresentado. Além disso, esse trabalho agrícola remete a um espaço determinado: a roça, símbolo do poder colonial, que foi, depois independência, associada aos trabalhos obrigatórios nos anos setenta. A roça era também considerado como lugar insalubre abandonado pelo Estado nos anos oitenta, habitado por pobres, sem infraestruturas. As antigas dependências agrícolas anexadas às casas grandes e seu conjunto formavam ainda o que tinha sobrado das roças coloniais carregando em si o peso da história, as desigualdades relacionadas a uma hierarquia social herdada e consolidada pelo governo independente. Diante da impossibilidade em vislumbrar uma ascensão socioeconômica, os descendentes dos serviçais não tinham nenhuma possibilidade em competir ou se associar a membros das classes políticas do país. Nascimento (2001, p. 220) considera que: "Em termos gerais, a liderança política tornou-se foro dos elementos da elite nativa não tendo cabido a angolares, cabo-verdianos e tongas ${ }^{38}$ um papel político significativo". Um dos primeiros dados que aponto aqui é que a ideia de paradoxo da invisibilidade social (consolidada pelas políticas governamentais locais) se exemplifica com o fato de ser notória a participação da mão de obra agrícola imigrante na vida agrícola do país e ao mesmo tempo dela estar

\footnotetext{
${ }^{37}$ Expressão analisada em outro artigo (BERTHET, 2012).

${ }^{38}$ A palavra Tonga se refere aos descendentes da mão de obra agrícola imigrante, antigos serviçais ou contratados, já nascidos em São Tomé e Príncipe.
} 
totalmente ausente da vida política ${ }^{39}$ no período pós-independente, já que os integrantes do Partido se consideravam os defensores e porta-voz legítimos dos descendentes dos serviçais.

Autores como Seibert apontam para a participação dos tongas em algumas greves e manifestações. O autor cita por exemplo, uma greve de 24 horas organizada pelo MLSTP em 1963 e que contou (segundo avaliação dos organizadores) com a participação de $90 \%$ dos trabalhadores (de diversos sectores). Segundo Seibert (2002, p. 104), trabalhadores da roça Diogo Vaz entraram também em greve depois que um dos trabalhadores foi demitido e começaram a participar de manifestações que ocorriam na cidade.

No entanto, essas manifestações políticas constituem, a meu ver, fatos pontuais que não levaram à constituição de grupos políticos de tongas/cabo-verdianos dentro das roças, por exemplo. As redes sociais associações, etc. - foram organizações que apareceram de forma paralela na vida política oficial no final dos anos noventa. Os trabalhadores agrícolas começaram a desenvolver estratégias diversas, reagindo assim ao fracasso da nacionalização das terras. Essas estratégias visaram a priorizar as suas necessidades mais imediatas. Uma delas, já iniciada antes do fim do regime colonial, era a apropriação ilegal de terras consideradas impróprias para a cultura de cacau. Muitos moradores de roças mantiveram nessas terras uma agricultura de subsistência para suas famílias. Seus campos eram estabelecidos à margem das roças de cacau ou então em outros espaços agrícolas de difícil acesso e aí produziam milho, cana-de-açúcar, hortaliças, legumes e leguminosas. Alguns, entre os mais idosos, ainda criavam cabras e porcos. Várias práticas e estratégias de apropriação das terras foram sendo desenvolvidas: o arrendamento das terras, a compra de terras com ou sem título de posse, o usufruto ilegal de lavras e de campos dentro das empresas ou em troca de um aluguel. Os antigos trabalhadores e seus descendentes, ou seja,

\footnotetext{
${ }^{39}$ Essa invisibilidade e ausência na vida política se caracterizam por exemplo pela ausência de trabalhadores agrícolas nos processos de negociações da Independência. Onde estavam, os moradores das roças no momento da declaração oficial da Independência de São Tomé e Príncipe? Alguns entrevistados afirmaram ter ouvido a notícia pela rádio e comentaram que vários caminhões foram deslocados até as roças para buscar os seus moradores e levá-los até a praça Yon Gato. Muitos dos trabalhadores que chegaram no início dos anos cinquenta não se referem ao 12 de julho como data da Independência de STP, mas ao 25 de abril (de 1974, que corresponde à revolução dos cravos), que, para eles, correspondem a um momento de invasão dos forros nas roças para organizarem sessões de pilhagem, roubando bens deixados pelos brancos nas casas-grandes ou, ainda, madeiras, telhas e todos outros materiais que poderiam ser utilizados para a construção de casas.
} 
"os de roça" agrária que se iniciou em 1993 porque se tornaram atores agrícolas reconhecidos e beneficiários de terras. Porém, sua ausência contínua na cena política nacional os leva a não ter representantes capazes de reivindicar e defender seus direitos ${ }^{41}$, já que até hoje não conquistaram um lugar influente na sociedade são-tomense. Isso levou a maioria dos Cabo-verdianos a interferir em redes paralelas, a desenvolver, como foi dito, estratégias diversas de sobrevivência num contexto de reforma agrária, mas que os priva ainda - a eles, Cabo-verdianos, os principais atores da vida agrícola do país - dos seus direitos de cidadania.

A classe dos antigos assalariados agrícolas, dominada na cena política, passou a construir diversas redes de atuação para garantir sua sobrevivência. Foi provavelmente nessa atuação "invisível" que os trabalhadores agrícolas consolidaram seus saberes, conhecimentos, redes comerciais, ênfase nas relações amistosas (prática do compadrio, redes de solidariedade através do djuntamon, criação de associações, rituais relativos aos mortos) e passaram a se organizar através de redes paralelas ${ }^{42}$. Em termos de conhecimentos agrícolas, os antigos trabalhadores agrícolas e seus descendentes se destacaram no uso de trapiche para fabricação de aguardente, cultivo de diversos produtos alimentares (cana de açúcar, leguminosas, milho) e criação de porcos (cabras e galinhas). São herdeiros e falantes do crioulo de Cabo Verde, de estilos musicais consumidos em São Tomé e Príncipe. Atores ativos da resistência ao colonialismo, os Tongas passaram a ser considerados os mais reivindicativos e rebeldes contra "os brancos" 43 nos últimos anos do regime. Existe uma aceitação, ainda que parcial, de que os Cabo-Verdianos são os verdadeiros atores da história agrícola das ilhas, os que trabalharam e continuam trabalhando a terra e enfrentaram os roceiros portugueses, no quotidiano colonial das roças.

\footnotetext{
${ }^{40}$ Um senhor de idade me precedia no caminho em direção aos correios, na cidade capital São Tomé e foi quase atropelado por um carro cujo motorista apressado se irritava diante da sua dificuldade em atravessar a faixa pedestre. Chocado pela impaciência do motorista, o senhor falou bem alto: "Eu não sou de roça não". Entendi que essa observação permitia entender o conjunto de representações e preconceitos construídos sobre os moradores de roças. Seriam pessoas "atrasadas" que não dominam os códigos da cidade como, por exemplo, atravessar rapidamente uma rua enquanto um carro espera.

${ }^{41}$ Nota-se a presença de um candidato (descendente de cabo-verdianos) à Presidência da República nos anos 2000 e a participação de alguns descendentes de cabo-verdianos na esfera do setor de associações, ONG's.

${ }^{42}$ Valverde mostrou com pertinência como os curandeiros Angolares mais temidos das ilhas pertencem a grupos marginalizados.

${ }^{43}$ Entrevista realizada no dia 11/02/2005, ilha de São Tomé.
} 
Entre representações locais, História oficial e redes paralelas que atribuem papéis diferentes aos atores sociais das ilhas de São Tomé e Príncipe, a comemoração da Independência e da nacionalização das terras se tornou progressivamente uma manifestação pública ligada à reificação da Nação são-tomense. A análise de Eyzaguire (1988, p. 7) sobre a atuação política das elites são-tomense pode ser considerada como uma avaliação relevante da situação do final dos anos oitenta e que perdurou apesar da reforma agrária dos anos noventa “(...) A concentração de terra fez parte de um processo político através do qual as elites e as suas instituições governamentais controlaram o acesso à terra e outros recursos naturais como instrumento para assegurar a sua hegemonia política". Com esse contexto político, as Organizações Não Governamentais nacionais e estrangeiras, instaladas em São Tomé e Príncipe, acompanharam e seguiram a política agrícola desenvolvida pelo governo. Uma das posturas dessas ONGs foi apoiar a distribuição de terra aos novos pequenos agricultores (antigos trabalhadores agrícolas do Estado) e participaram, por exemplo, da implementação de atividades ou projetos de "aldeamento" planejada pelo governo. Esta política de "aldeamento" 44 visava a constituição de verdadeiras comunidades que poderiam substituir o sistema das antigas roças. Sem dúvida, a presença das ONGs levou a reivindicações constantes dos novos pequenos agricultores para melhorar suas condições de vida, de moradia e de ajuda para o trabalho agrícola. Ao mesmo tempo, a atuação das ONGs mascarou diversas práticas políticas que levaram a favorecer por exemplo os médios empresários ou ainda a distribuir parcelas de 1,5 ha aos ex-trabalhadores agrícolas com muitos declívios e em péssimo estado conforme a afirmação de diversos entrevistados. Além disso, muitos dos contratados do tempo colonial que posteriormente foram trabalhadores agrícolas do Estado não se beneficiaram de nenhuma parcela de terra e foram agregados como dependentes dos seus filhos.

Apesar de algumas mudanças efetivas na vida dessa nova geração de moradores de roças, o "paradoxo da invisibilidade" perpetuou-se. Em 2000, com o fim do programa de reforma agrária, um recenseamento afirmava que existia de 6300 pequenos agricultores e 170 médios empresários (SEIBERT, 2007, p. 979) ${ }^{45}$. Apesar do reconhecimento do papel preponderante da mão de obra agrícola das roças no período

\footnotetext{
${ }^{44}$ A proposta lembra o projeto do governo colonial, de 1947, de fixação de mão-de-obra.

${ }^{45}$ Segundo informações do Gabinete de Reforma Fundiária apresentadas por Temudo já foram entregues ( 8 anos depois) cerca de 19808 ha a um total de 9129 pequenos agricultores, devido à distribuição subsequente da área da maioria das grandes empresas.
} 
colonial e na produção de produtos alimentares (oriundos das pequenas parcelas de terra recebidas) no pós-reforma agrária, os sucessivos governos nacionais implementaram políticas que consolidaram a marginalização desses atores. No entanto, essa invisibilidade política e social, reforçada pelos estereótipos e os estigmas criados no seio da sociedade são-tomense, não imobilizou esses atores que foram se afirmando em outras versões da história official. Eles reconstruíram uma subjetividade social capaz de dar novos significados a tempos mais difíceis de sua existência, atuando em algumas esferas do comércio agrícola e superando a condição de serviçal retratada no resumo do conto.

\section{Referências}

ANDRADE, PINTO (DE), Mário. Origens do Nacionalismo Africano. Lisboa: Dom Quixote, 1997.

BARROS, V. A. R. Reforma agrária e suas perspectivas em São Tomé e Príncipe. In: Comum, IICT, Série Ciências Agrárias, n. 19, p. 241-248, 1995.

BERTHET, M. Ceux qui sont de passage et ceux qui restent. L'émigration capverdienne à São Tomé et Príncipe. In: BARROS, Denise Dias; BERTHET, Marina; ABDALLA, Mustafa (Org.). New Perspectives on Migration in African Settings. Cologne: Rudiger Koppe Verlag, 2014. Vol. 35, p. 1-205.

. Projet de développement et communautés rurales dans la réforme foncière à São Tomé et Príncipe. DEA en Sciences Sociales. Marseille: EHESS, 1999. Rio, 2으. 2012.

CARREIRA, António. Migrações nas ilhas de Cabo Verde. Cabo Verde: Instituto Cabo-verdeano do Livro, 1977.

CEITA, Maria Nazaré. A reforma agrária em São Tomé e Príncipe: período póscolonial. Tese (Doutorado em História da África) - Faculdade de Letras, Universidade de Lisboa, 2001.

ELLISON, Ralph. The invisible man. New York: Random House, 1952.

ESPÍRITO SANTO, Carlos. Almas de elite santomenses. Lisboa, 2000.

EYZAGUIRE, Pablo. Small Farmers and Estates in São Tomé, West Africa. Tese (Doutorado) - Yale University, 1986.

Competing Systems of Land Tenure in an African Plantation Society. In: DOWNS, R.; REYNA, S. (Eds.). Land and Society in Contemporary Africa. Hannover: N.H., University Press of New England, 1988. p. 340-361.

. The Independence of São Tomé e Príncipe and Agrarian Reform. In: The jornal of Modern African Studies, n. 27, v. 4, p. 671-679, 1989.

GONÇALVES, Manuel Joaquim Sobral. Angolares: uma aproximação antropológica. In: Geographica. Revista da Sociedade de Geografia de Lisboa, v. IX, n. 34, p. 77-94, 1973. 
HENRIQUES, Isabel Castro. São Tomé e Príncipe - A invenção de uma Sociedade. Lisboa: Vega, 2000.

HONNETH, Axel. Invisibilité: sur l'épistémologie de la "reconnaissance". In: Réseaux, v. 129/130, n. 1-2 (Visibilité/Invisibilité), p. 39-57, 2005.

HODGES, Tony, MALYN, Newitt. São Tomé and Príncipe. From Plantation Colony to Microstate. Londres: Westview, 1998.

KEESE, Alexander. Early Limits of Local Decolonization in São Tomé and Príncipe: From Colonial Abuses to Postcolonial Disappointment, 1945-1976. In: International Journal of African Historical Studies, v. 44, n. 3, p. 373-392, 2011.

LE BLANC, Guillaume. L'invisibilité sociale. Paris: PUF, 2009.

MAINO, Elisabetta. À propos de "l'africanité" de São Tomé et Principe (On the “Africanicity” of São Tomé and Príncipe). In: Cahiers d'Études africaines, v. 42, p. 385-396, jan. 2001.

MANTERO, Francisco. Mão d'obra em S. Tomé e Príncipe. Lisboa: [s.n.], 1910.

MASSA, Françoise et Jean-Michel. Fablier de São Tomé. Paris: Edicef, 1984.

MATA, Inocência Diálogo com as Ilhas - sobre cultura e literatura de São Tomé. Lisboa: Edições Colibri. 1998.

NARTEY, Robert Nii. From slave to serviçal: Labor in the plantation economy of São Tomé and Principe. Chicago: Univ. Illinois, 1986.

NASCIMENTO, Augusto. Mutações sociais e politicas em São Tomé e Príncipe nos séculos $X I X-X X$ : uma síntese interpretativa. Comunicação apresentada no Centro Cultural Português de São Tomé e Príncipe. São Tomé e Príncipe, 2001.

. Poderes e Quotidiano nas Roças de S. Tomé e Príncipe de finais de oitocentos a meados de novecentos, Lousã: Apoio de Sociedade de Promoção de Investimentos, 2002.

RELATÓRIO do Movimento de Libertação. República de São Tomé e Príncipe, 1aㅡ Assembleia do MLSTP, Relatório do Bureau Político, 1978.

ROMANA, Heitor, A. C. São Tomé e Príncipe. Elementos para uma análise antropológica das suas vulnerabilidades. Lisboa: Instituo Superior de Ciências Políticas, Universidade técnica, 1997.

SANTOS, Catarina Madeira. A formação das estruturas fundiárias e a territorialização das tensões sociais: São Tomé, primeira metade do século XVI. In: Studia, n. 54/55, p. 51-91, 1996.

SEIBERT, Gerhard. Camaradas, Clientes e Compadres. Lisboa: Vega, 1999.

. The Bloodless Coup of July 16 in São Tomé e Príncipe. In: Lusotopie. Paris, Karthala, 2003. p. 245-260.

. A Verdadeira Origem do Célebre Rei Amador, líder da revolta dos escravos em 1595. Piá, São Tomé e Príncipe, v. 26, p. 10-11, 2005.

. São Tomé and Príncipe. Recent History. In: Africa South of the Sahara. Londres: Routledge, 2007. p. 972-987.

TEMUDO, Marina. De serviçal a camponês. A persistência das desigualdades sociais em São Tomé e Príncipe In: Lusotopie. XV/2, Histoires d'Asie, 2008. 
TRAJANO Filho, Wilson. Invisíveis e Liminares - a sociedade crioula e seus heróis. In: Soronda: revista de estudos Guineenses, n. 18, p. 77-113, jul. 1994.

VALVERDE, Paulo. Máscara, Mato e Morte em São Tomé. Oeiras: Celta, 2000.

Recebido: 15 de fevereiro de 2016 Aprovado: 22 de maio de 2016

\section{Autora/Author:}

MARINA BERTHET <marinaannie@gmail.com>

- Professora de História da África - PPGH/GH da Universidade Federal Fluminense. Doutora em Antropologia Social pela USPFFLCH. Realizou trabalhos de campo no Benim e São Tomé e Príncipe, tendo se dedicados aos estudos em Ciências Sociais sobre África, Antropologia do desenvolvimento, Tradição oral e suas relações com escrita, universo pós-colonialista, trabalho forçado, colonialismo, formas expressivas e migrações. Organizou recentemente, para a Revista em Ciências Sociais (UFC), o dossiê Trabalho em África no Tempo Colonial (2015).

- Professor of History of Africa (PPGH/GH) at the Universidade Federal Fluminense. PhD in Social Anthropology from Universidade de São Paulo. She has done field work at Benin and São Tomé and Principe, dedicating herself to the studies in Social Sciences about Africa, Anthropology of development, oral Tradition and its relationships with writhing, post-colonialist universe, forced labor, colonialism, expressive forms and migrations. Recently organized, to the Revista em Ciências Sociais (UFC), the dossier Trabalho em Africa no Tempo Colonial (2015). 